\title{
Profiling of testis-specific long noncoding RNAs in mice
}

\author{
Seong Hyeon Hong, Jun Tae Kwon, Jihye Kim, Juri Jeong, Jaehwan Kim, Seonhee Lee and Chunghee Cho*
}

\begin{abstract}
Background: Spermatogenesis, which is the complex and highly regulated process of producing haploid spermatozoa, involves testis-specific transcripts. Recent studies have discovered that long noncoding RNAs (IncRNAs) are novel regulatory molecules that play important roles in various biological processes. However, there has been no report on the comprehensive identification of testis-specific IncRNAs in mice.

Results: We performed microarray analysis of transcripts from mouse brain, heart, kidney, liver and testis. We found that testis harbored the highest proportion of tissue-specific IncRNAs (11\%; 1607 of 14,256). Testis also harbored the largest number of tissue-specific mRNAs among the examined tissues, but the proportion was lower than that of IncRNAs (7\%; 1090 of 16,587). We categorized the testis-specific IncRNAs and found that a large portion corresponded to long intergenic ncRNAs (lincRNAs). Genomic analysis identified 250 protein-coding genes located near ( $\leq 10 \mathrm{~kb}) 194$ of the loci encoding testis-specific lincRNAs. Gene ontology (GO) analysis showed that these protein-coding genes were enriched for transcriptional regulation-related terms. Analysis of male germ cell-related cell lines (F9, GC-1 and GC-2) revealed that some of the testis-specific IncRNAs were expressed in each of these cell lines. Finally, we arbitrarily selected 26 testis-specific IncRNAs and performed in vitro expression analysis. Our results revealed that all of them were expressed exclusively in the testis, and 23 of the 26 showed germ cell-specific expression.
\end{abstract}

Conclusion: This study provides a catalog of testis-specific IncRNAs and a basis for future investigation of the IncRNAs involved in spermatogenesis and testicular functions.

Keywords: cis-acting, Long noncoding RNA, Spermatogenesis, Testis, Testis-specific IncRNAs

\section{Background}

Spermatogenesis is the complex and tightly regulated differentiation process through which haploid spermatozoa are produced in the seminiferous tubules of the testis. This process can be divided into three successive phases: the mitotic division of spermatogonia, the meiosis of spermatocytes and the morphological change of spermatids during spermiogenesis [1]. It is expected that a highly organized intrinsic genetic network is responsible for controlling spermatogenesis in the testis, and that the elucidation of the underlying molecular mechanism will help us further understand male germ cell development. The previous studies have largely focused on identifying and characterizing protein-coding genes [2] and small noncoding RNAs, such as microRNAs (miRNAs) [3] and

\footnotetext{
* Correspondence: choch@gist.ac.kr

School of Life Sciences, Gwangju Institute of Science and Technology, Gwangju 61005, Korea
}

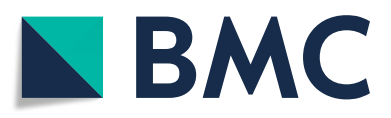

(c) The Author(s). 2018 Open Access This article is distributed under the terms of the Creative Commons Attribution 4.0 International License (http://creativecommons.org/licenses/by/4.0/), which permits unrestricted use, distribution, and reproduction in any medium, provided you give appropriate credit to the original author(s) and the source, provide a link to the Creative Commons license, and indicate if changes were made. The Creative Commons Public Domain Dedication waiver (http://creativecommons.org/publicdomain/zero/1.0/) applies to the data made available in this article, unless otherwise stated.

piwi-interacting RNAs (piRNAs) [4], in the mouse testis. However, a recent transcriptomic analysis revealed that there is pervasive transcription of long noncoding RNAs (lncRNAs) in the mouse testis [5].

LncRNAs are arbitrarily defined as noncoding RNAs longer than 200 nucleotides. Compared with protein-coding transcripts, they tend to be shorter and have lower expression levels, fewer exons, less sequence conservation and more tissue and cell type-specific expression patterns [6-11]. Studies have shown that lncRNAs are novel regulatory molecules involved in processes of genetic regulation, including transcription [12, 13], epigenetic modification [14, 15], alternative splicing of pre-mRNAs $[16,17]$ and mRNA stabilization or decoy functions $[18,19]$. IncRNAs have also been shown to play important roles in other biological processes, including cell differentiation [19-21] and tissue development [21, 22]. 
Recent studies have identified lncRNAs in the mouse testis and examined their biological roles during male germ cell development [23-27]. However, although numerous studies have investigated the protein-coding genes that show tissue-specific expression and play important roles during spermatogenesis, no previous study has comprehensively identified and characterized the mouse testis-specific lncRNAs.

Here, we used microarray analysis to profile the previously annotated lncRNAs and mRNAs expressed in various mouse tissues, including testis. By comparing the lncRNA and mRNA expression profiles among the tissues, we identified lncRNAs and mRNAs that showed differential expression in each tissue. We found that testis has the largest number of tissue-specific lncRNAs. We also profiled lncRNA and mRNA expression in three mouse male germ cell-related cell lines (F9, GC-1 and GC-2). To the best of our knowledge, this is the first study to identify mouse testis-specific lncRNAs and analyze their characteristics. Our data provide a valuable resource for future investigation of the lncRNAs that are involved in male germ cell development and testicular functions.

\section{Results}

\section{Identification of IncRNAs and mRNAs in mouse tissues}

To identify lncRNAs and mRNAs expressed in major tissues (brain, heart, kidney, liver and testis) in ICR mice and germ cell-related cell lines (F9, GC-1 and GC-2) in mice, we performed a microarray analysis using the Arraystar mouse lncRNA microarray V3.0, which contains probes for 35,923 lncRNAs and 24,881 mRNAs
(Fig. 1). The expression profiles obtained from this analysis are summarized in Table 1 and Additional file 1.

The maximal numbers of both lncRNAs $(14,256)$ and mRNAs $(16,587)$ were observed in testis compared to the other tissues, suggesting that testis is characterized by a high level of transcriptomic diversity and complexity. To perform tissue-specific expression profiling, we compared the expression levels of transcripts among the five tissues across three microarray experiments and classified the transcripts as present $(\mathrm{P})$, marginal $(\mathrm{M})$ or absent $(\mathrm{A})$ of which expression level was lower than the background level. We regarded a transcript as a tissue-specific lncRNA or mRNA with the expression showing a fold-change $\geq 5$ and $P$-value $\leq 0.05$ for a tissue relative to the others and with three independent $\mathrm{P}$ or $\mathrm{M}$ only in the tissue. We found that testis exhibited the largest numbers of tissue-specific lncRNAs (1607) and mRNAs (1090) among the analyzed tissues (Table 1, Fig. 2a and Additional file 2). The testis-specific lncRNAs were more abundant than the testis-specific mRNAs, even though there were fewer total lncRNAs than mRNAs in this tissue (Fig. 2b). We speculated that these newly identified testis-specific lncRNAs could be involved in regulating testicular gene expression and/or functions.

To validate our microarray-based selection of tissue-specific lncRNAs, we performed quantitative real-time PCR (qRT-PCR) on several arbitrarily selected tissue-specific lncRNAs (Fig. 3). As controls, we used ENSMUST00000161380, an lncRNA that is predicted to be ubiquitously expressed and the transition protein 1 (Tnp1) gene, which encodes a testis-specific mRNA [28]. The tissue-specific lncRNAs subjected to

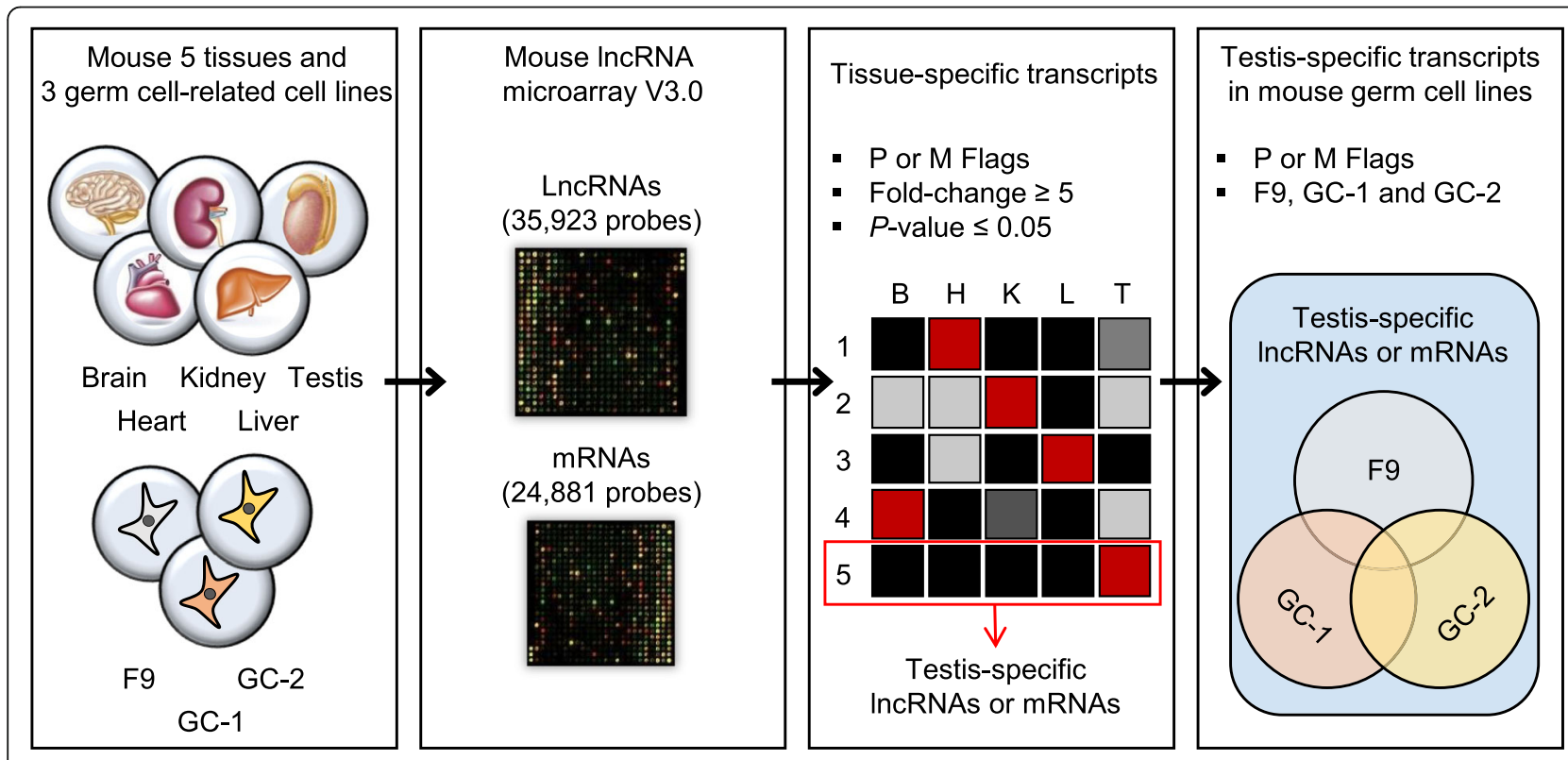

Fig. 1 Schematic diagram of the expression profiles of IncRNAs and mRNAs in mouse major tissues and germ cell-related cell lines 
Table 1 Summary of the microarray results obtained in five mouse tissues and three mouse cell lines

\begin{tabular}{llllc}
\hline & IncRNAs & mRNAs & IncRNAs & mRNAs \\
\hline Tissues & \multicolumn{2}{l}{ Total expressed } & \multicolumn{2}{l}{ Specifically expressed } \\
Brain & 12,832 & 15,579 & 595 & 553 \\
Heart & 10,086 & 13,354 & 104 & 89 \\
Kidney & 9915 & 13,319 & 102 & 106 \\
Liver & 6290 & 9431 & 48 & 76 \\
Testis & 14,256 & 16,487 & 1607 & 1090 \\
Germ cell-related cell lines & Total expressed & Testis-specific \\
F9 & 9065 & 12,512 & 128 & 187 \\
GC-1 & 10,571 & 13,492 & 143 & 167 \\
GC-2 & 10,652 & 13,443 & 126 & 175 \\
\hline
\end{tabular}

a
No. of tissue-specific IncRNAs:
1,607
48104102
595

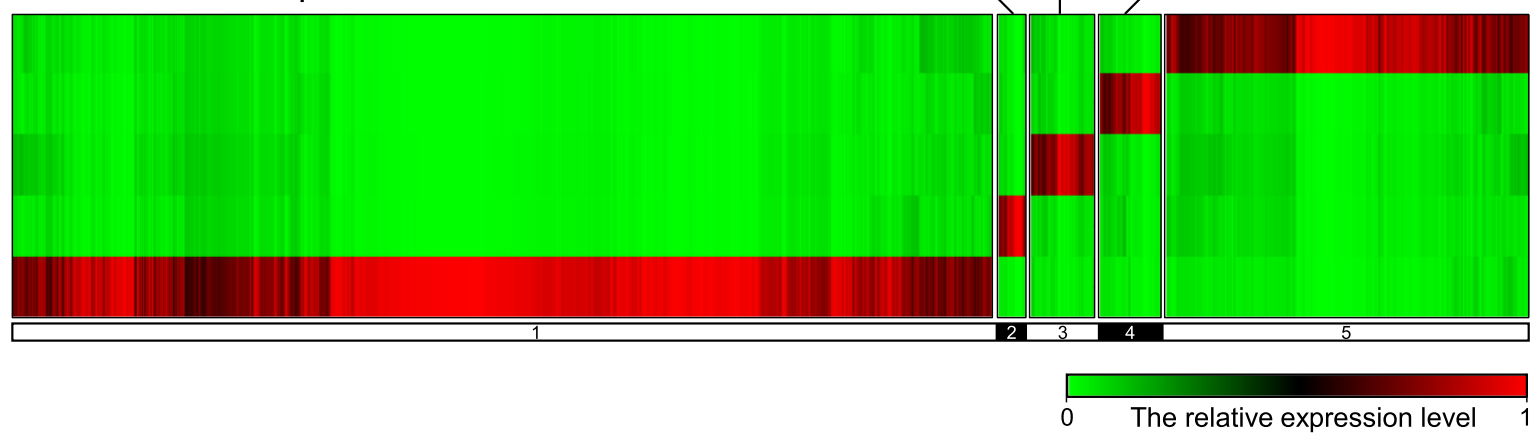

b

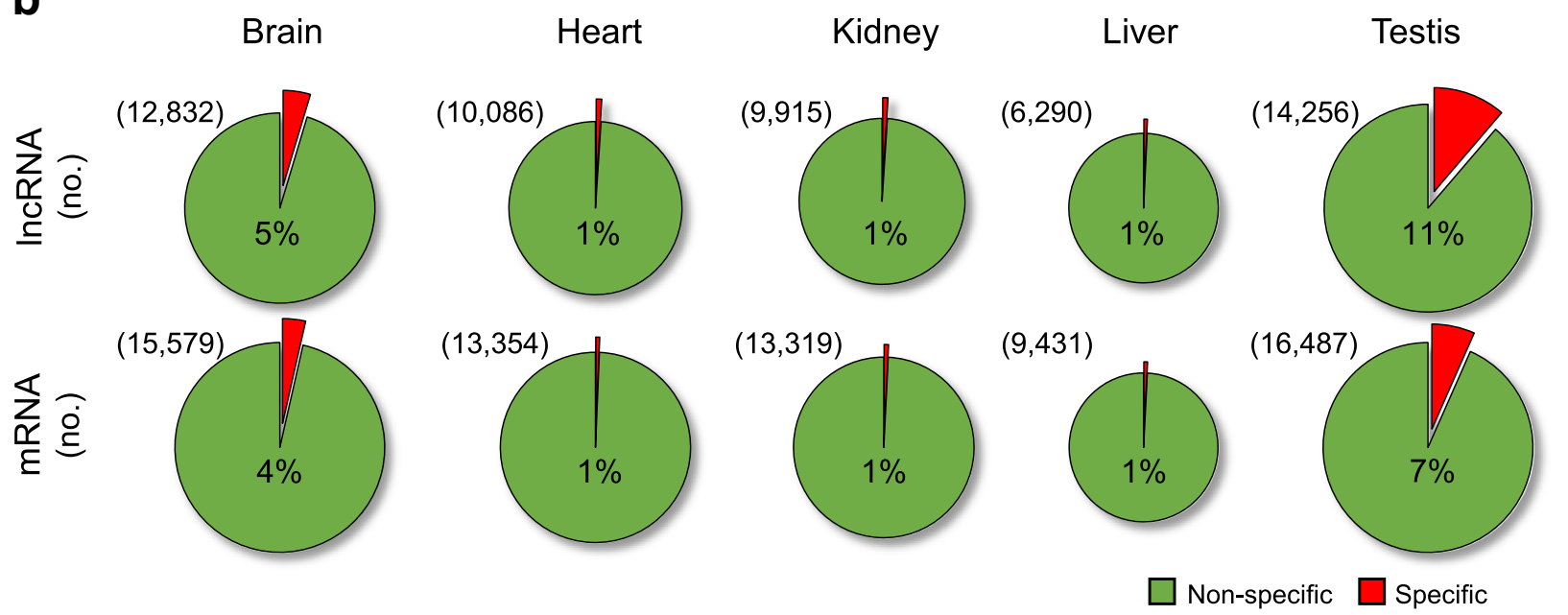

Fig. 2 Characteristics of the identified tissue-specific IncRNAs and mRNAs. a Heat map showing the relative expression levels of the InCRNAs that exhibited differential expression in five major mouse tissues. Red and green colors indicate higher and lower expression levels, respectively. $\mathbf{b}$ The percentage of tissue-specific IncRNAs and mRNAs in each mouse tissue
qRT-PCR analysis were ENSMUT00000125184 (brain), ENSMUST00000125187 (heart), NR_102276 (kidney), ENSMUST00000120145 (liver), NR_038002 (testis) and AK018904 (testis). Our qRT-PCR analysis demonstrated that these IncRNAs were specifically or predominantly expressed in the corresponding tissues

\section{Chromosomal distribution of testicular IncRNAs}

To characterize the genomic nature of the identified testicular IncRNAs and mRNAs, we examined the chromosomal localization of the loci that expressed these anscripts. Our analysis revealed that they were widely throughout the mouse chromosomes. mosome 5 and the $\mathrm{X}$ chromosome contain the numbers of loci for testis-specific lncRNAs and NAs, respectively (Fig. 4a and Additional file 3). To examine whether one or more chromosomes were enriched with testis-specific lncRNAs and mRNAs, we compared the ratio of testis-specific transcripts to 

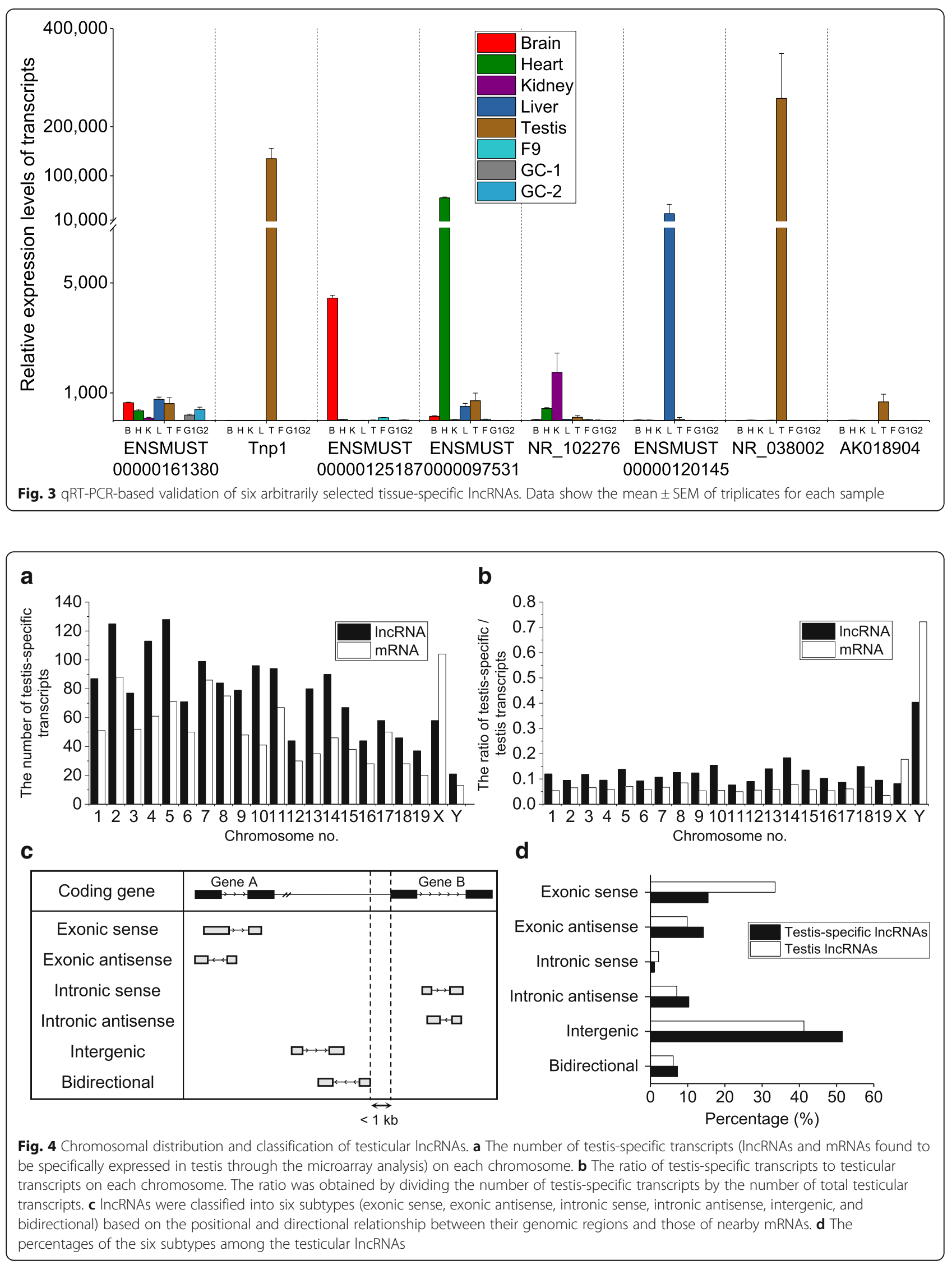
total testicular transcripts among chromosomes (Fig. 4b). The ratio was similar among the chromosomes, except for the sex chromosomes: the ratios of testis-specific lncRNAs and mRNAs were both remarkably high for the Y chromosome, even though relatively few loci on this chromosome expressed testis-specific transcripts (21 testis-specific lncRNAs and 13 testis-specific mRNAs). Based on this finding, we speculate that the expressions of testis-specific lncRNAs and mRNAs may be related on the $\mathrm{Y}$ chromosome, perhaps through cis-regulation between the two groups of testis-specific transcripts.

\section{Classification of testicular IncRNAs}

We categorized all of the identified lncRNAs based on the position and direction of their genomic regions relative to nearby mRNAs. The lncRNAs were classified into six subtypes: exonic sense, exonic antisense, intronic sense, intronic antisense, intergenic and bidirectional (Fig. 4c and Additional file 4). If an lncRNA overlapped with the exon or intron of a coding gene with the same or opposite direction, it was called exonic sense, exonic antisense, intronic sense or intronic antisense, respectively. A bidirectional lncRNA was defined as a transcript whose locus was less than $1 \mathrm{~kb}$ from an mRNA-encoding region, regardless of its direction. Finally, a genomic locus more than $1 \mathrm{~kb}$ from any mRNA-encoding genomic region was considered to be a long intergenic ncRNA (lincRNA). Using this classification scheme, we found that the majority of testis-specific (51.6\%) and testicular (41.2\%) lncRNAs were lincRNAs (Fig. 4d).

Because many lincRNAs are known to act in a cis-regulatory manner [29, 30], we investigated the potential cis-regulatory targets of 829 testis-specific lincRNAs by searching for protein-coding genes within $10 \mathrm{~kb}$ up- and downstream of their encoding loci. We found that 23.4\% (194 of 829) of the lincRNAs co-localized with 250 protein-coding genes (Additional file 5). Interestingly, some of these genes are testis-specific or predominant genes (e.g., Tnp1, Glt6d1, 1700018C11Rik, Speer4e, Spata31d1d, Tmco5, Spata17, 1700080E11Rik, Rcc1, Agbl3 and 1700057G04Rik), suggesting the expression regulation of these genes by the lincRNAs through transcriptional or post-transcriptional mechanisms. Gene Ontology (GO) [31] analysis of all of the identified nearby protein-coding genes was performed to explore their functions. We found that 40 diverse $\mathrm{GO}$ terms were significantly enriched $(P$-value $\leq 0.05)$, including regulation of transcription DNA-templated (GO:0006355), transcription DNA-templated (GO:0006351), positive regulation of transcription from RNA polymerase II promoter (GO:0045944), negative regulation of transcription from RNA polymerase II promoter (GO:0000122) and cell differentiation (GO:0030154) (Additional file 6). This suggests that the testis-specific lincRNAs could potentially modulate the expression of genes that encode proteins involved in transcriptional regulation.

\section{Conservation of mouse testis-specific IncRNAs in human} Although lncRNAs generally show poor sequence conservation among species [8], we utilized the BLASTN program [32] to examine the sequence conservation between human lncRNAs and the mouse testis-specific lncRNAs identified in this study. Starting from the 1607 mouse testis-specific lncRNAs, we obtained genomic sequence information for 1508 (93.8\%) from diverse genome databases (e.g., UCSC genome browser, NCBI and Ensemble). When we used an $E$-value $\leq 10^{-5}$ as a cut off, we found that only $79(5.2 \%)$ of the mouse testis-specific lncRNAs were partially conserved in the human genome (Additional file 7). This indicates that testis-specific lncRNAs have low primary sequence conservation, and are thus likely to experience rapid evolution.

\section{Expression of testis-specific IncRNAs in germ cell lines}

To further characterize the testis-specific lncRNAs, we used microarray analysis to investigate their expression profiles in three relevant cell lines: F9, GC-1 and GC-2 (Fig. 1 and Additional file 8). F9 embryonal carcinoma cells are stem cells of testicular carcinoma, and have the ability to differentiate into three embryonic layers [33]. Although F9 cells are considered to be similar to embryonic cells, the former can transcribe germ cell-specific genes and possess the characteristics of male germ cells [34]. Immortalized GC-1 cells exhibit the characteristics of a stage between type B spermatogonia and primary spermatocytes [35], while GC-2 cells were derived from cells arrested at a premeiotic stage and exhibit the characteristics of spermatocytes [36]. Our analysis revealed that some of the testis-specific lncRNAs (14\%; 228 of $1607)$ and mRNAs (23\%; 260 of 1090) were detectable in one or more of the cell lines. When assessed individually, the various cell lines were found to express 128 (F9), 143 (GC-1) and 126 (GC-2) of the lncRNAs and 187 (F9), 167 (GC-1) and 175 (GC-2) of the mRNAs (Fig. 5 and Additional file 9). Thus, these cell lines should prove useful for the further characterization of certain testis-specific lncRNAs and mRNAs.

\section{In vitro expression of testis-specific IncRNAs}

As we initially identified our tissue-specific transcripts using only five tissues in our microarray analysis, we assessed whether the selected IncRNAs were indeed testis-specific by selecting 26 of them predicted to have relatively abundant expression, and using reverse transcription-polymerase chain reaction (RT-PCR) to examine their distribution in 10 mouse tissues. Our results showed that all 26 of the testis-specific lncRNAs were transcribed only in the mouse testis (Fig. 6). 


\section{a

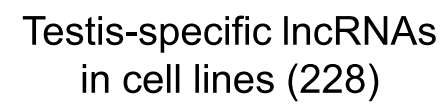

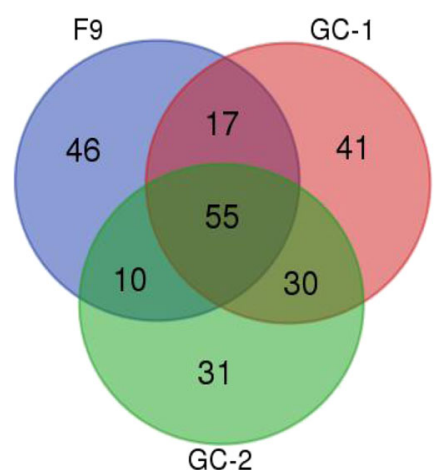

b

Testis-specific mRNAs in cell lines (260)

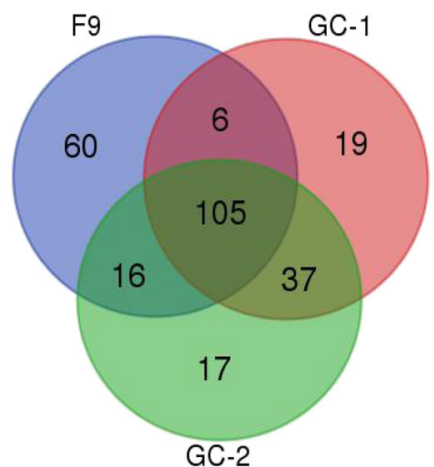

Fig. 5 Venn diagram showing the number of testis-specific IncRNAs and mRNAs in three mouse germ cell-related cell lines. a Two hundred twenty eight of the testis-specific IncRNAs were identified across the three cell lines. b Two hundred sixty testis-specific mRNAs were identified across the three cell lines

Next, we examined the germ cell-specific expression patterns of these 26 testis-specific lncRNAs using the germ cell-less testis of $W / W^{N}$ (c-kit) mutant mice [37]. This analysis showed that 23 of the testis-specific lncRNAs were absent from the testis of $W / W^{\nu}$ mutant mice (Fig. 7b), suggesting that they are germ cell-specific lncRNAs. The other three testis-specific lncRNAs may also be expressed in somatic cells of the testis.

Finally, we examined the developmental expression of these 26 testis-specific lncRNAs in mouse testis at different postnatal days. Spermatogonial stem cells gradually proliferate and differentiate to produce spermatogonia, spermatocytes and round spermatids during the first round of spermatogenesis in the prepubertal mouse [38]. Meiosis begins in the mouse testis at postnatal day 10 . At postnatal day 14, pachytene spermatocytes are highly enriched to about one-third of the total cells in the seminiferous tubules. Round spermatids appear in the seminiferous tubules at postnatal day 18 (Fig. 7a). If the testis-specific lncRNAs are expressed only in germ cells during the first round of spermatogenesis, they will first appear in the testis at a postnatal time that corresponds to a specific stage of spermatogenesis. Indeed, we found that four of the testis-specific IncRNAs were first expressed at postnatal day 14, suggesting that they are expressed in early-stage spermatocytes; three were first expressed at postnatal day 16, suggesting that they are expressed from pachytene spermatocytes; and 16 were first expressed at postnatal day 21, suggesting that they were expressed from round spermatids (Fig. 7b). These results suggest that most of the identified testis-specific lncRNAs are expressed specifically in spermatogenic cells, and their transcription appears to be regulated in a stage-dependent manner.

\section{Discussion}

Recent studies have shown that lncRNAs play important roles in regulating testicular development and spermatogenesis [26, 27]. Testis IncRNAs have been identified in mammalian species, including mouse [23-25], rat [39], pig [40] and human [5]. In mice, several studies have investigated the expression profiles of testis lncRNAs during postnatal development [23], during specific developmental stages of spermatogenesis [24] and at critical time points during male germ cell development [25]. In order to understand the unique and complicated features of the transcriptome in testis, we need to identify lncRNAs that are differentially expressed in testis relative to other tissues [5]. However, no previous study had set out to identify lncRNAs that are specifically or predominantly expressed the testis of mouse. To address this gap, we herein used microarray analysis to identify tissue-specific lncRNA transcripts in mouse brain, heart, kidney, liver and testis. We identified 14,256 lncRNAs and 16,487 mRNAs that were significantly expressed in mouse testis. Of them, 1607 lncRNAs and 1090 mRNAs were testis-specific. Among the studied tissues, testis had the most tissue-specific lncRNAs (11\%) and mRNAs (7\%). Notably, lncRNAs exhibited more testis specificity than mRNAs, suggesting that lncRNAs may be involved in male germ cell development.

We observed that the testis-specific IncRNAs and mRNAs were enriched on the $\mathrm{Y}$ chromosome relative to the other mouse chromosomes. Genes of the mammalian $\mathrm{Y}$ chromosome are known to play important roles in sex determination (e.g., Sry) [41] and spermatogenesis (e.g., Eif2s3y) [42], suggesting that the testis-specific lncRNAs of the $\mathrm{Y}$ chromosome deserve further investigation. The functions of IncRNAs cannot be predicted due to their poor sequence conservation and our lack of knowledge regarding 


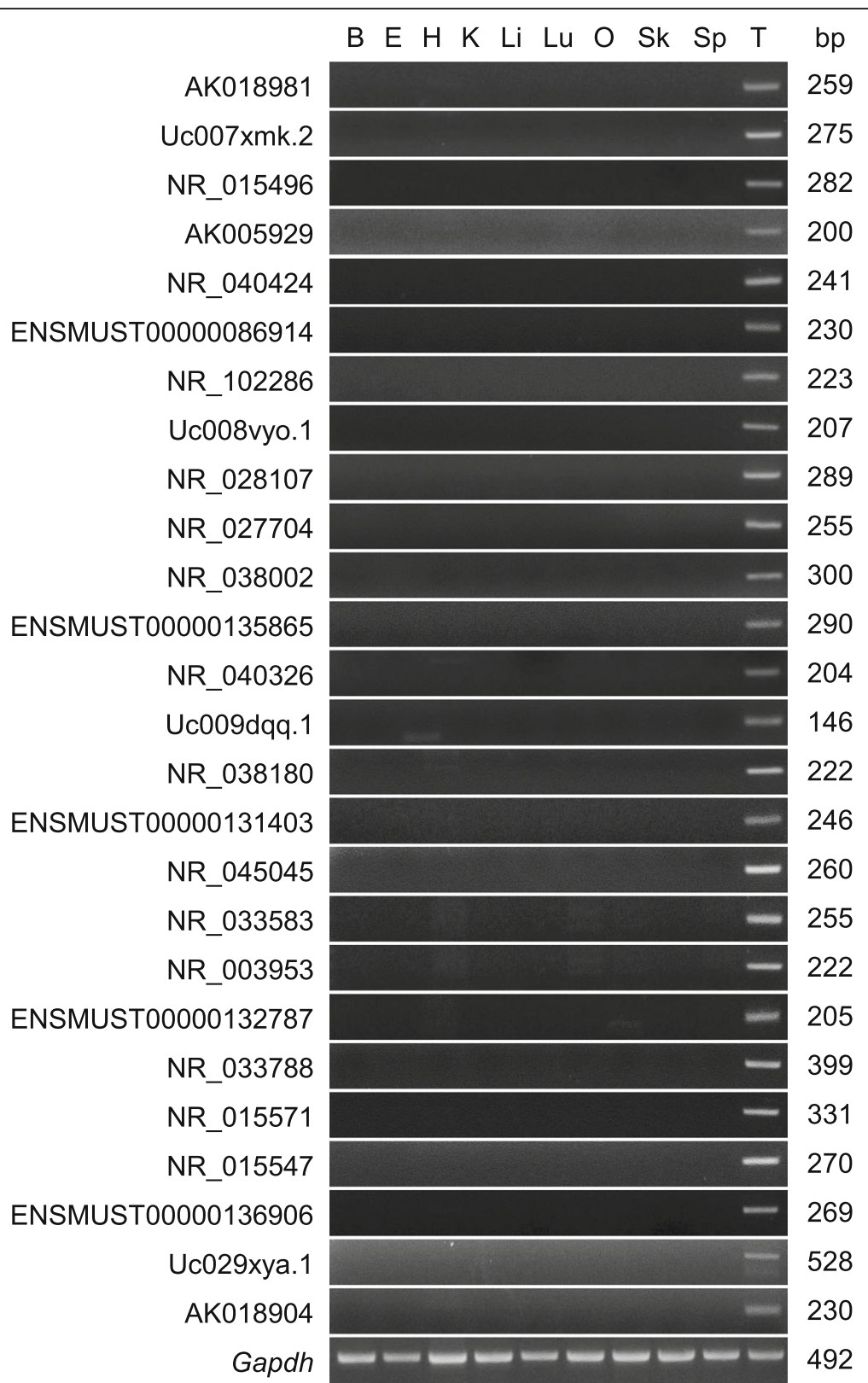

Fig. 6 Tissue distribution of 26 arbitrarily selected novel testis-specific IncRNAs in 10 mouse tissues, as assessed by RT-PCR. The results were normalized with respect to the band intensity of glyceraldehyde-3-phosphate dehydrogenase (Gapdh). B, Brain; E, Epididymis; H, Heart; K, Kidney; Li, Liver; Lu, Lung; O, Ovary; Sk, Skeletal muscle; Sp, Spleen; and T, Testis

relevant functional motifs and domains in protein-coding genes. However, a number of studies have inferred the putative functions of lncRNAs by examining their genomic relationships with protein-coding genes, and some lncRNAs have been shown to regulate the expression of their overlapping or neighboring protein-coding genes [43]. We herein identified several subtypes of lncRNAs, and found that lincRNAs constituted the largest proportion of both testis and testis-specific lncRNAs [10]. We hypothesized that the testis-specific lincRNAs could act through a cis-regulatory mechanism, and thus identified and examined 250 protein-coding genes within the 10-kb regions up- and downstream of 194 testis-specific lincRNAs. Our GO analyses revealed that these genes were mainly involved in regulating transcription. It seems possible that the testis-specific lincRNAs could contribute to spermatogenesis through such function. Interestingly, some of the identified cis-acting target protein-coding genes are known to be involved in spermatogenesis (e.g., Tnp1 and Spata17), raising the possibility that the testis-specific lincRNAs could play direct regulatory roles in male germ cell development. Alternatively, they may act in trans by targeting protein-coding 
a

$\underbrace{\text { Mitotic phase }}_{\text {PLLZ Z }}$

b

Mouse age (postnatal day)

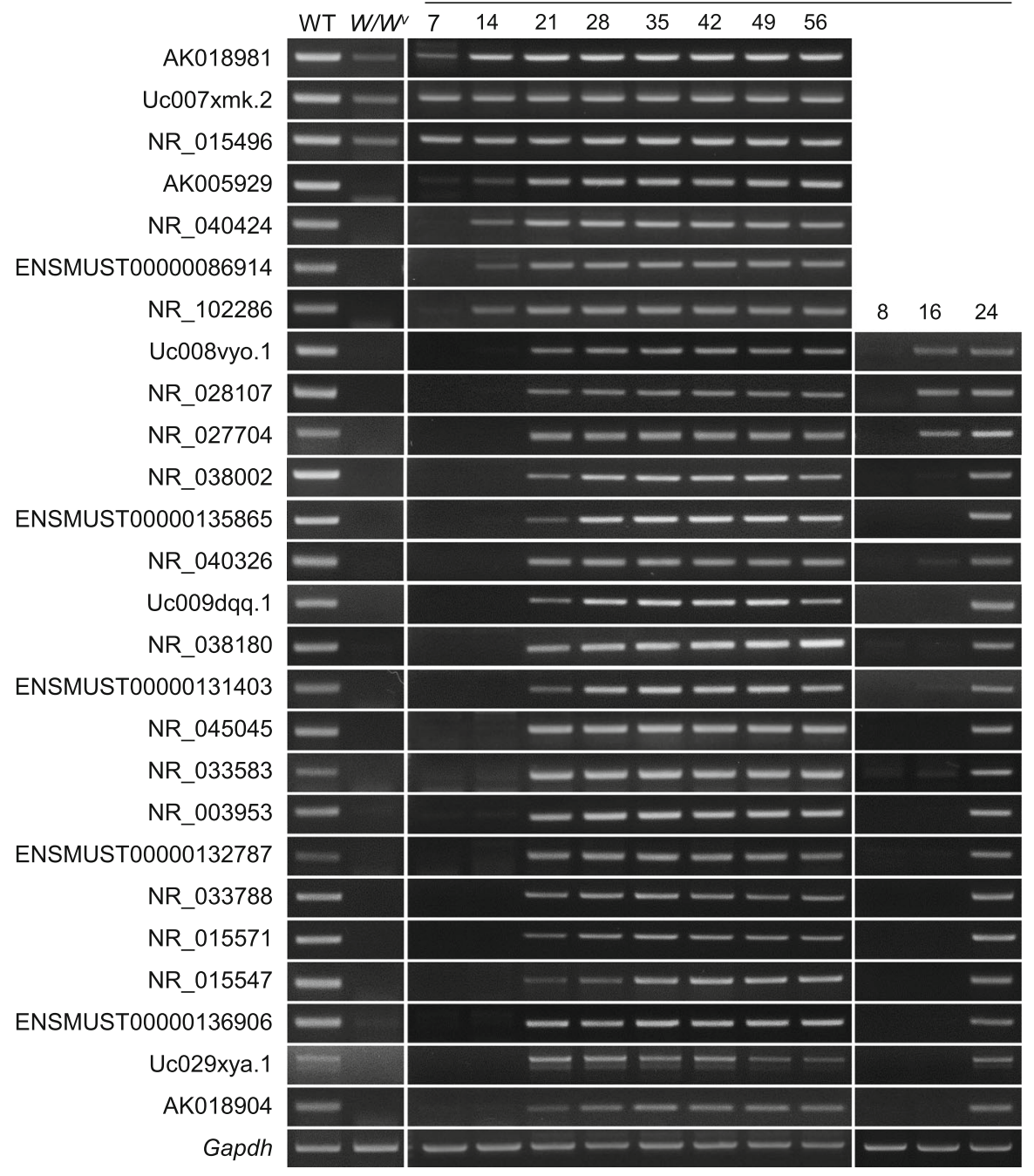

Fig. 7 Developmental expression patterns of the 26 novel testis-specific IncRNAs during the first round of spermatogenesis. a Schematic diagram showing the first round of spermatogenesis, which is composed of the mitotic, meiotic and postmeiotic phases. The meiotic phase consists of preleptotene (PL), leptotene (L), zygotene (Z), pachytene (P), diplotene (D), meiotic division I (MI) and meiotic division II (MII). b Developmental expression patterns of testis-specific IncRNAs in germ cell-lacking testes (W/W mutant mice) and wild-type mouse testes were assessed by RTPCR of samples taken at different postnatal days

genes located on the other mouse chromosomes. To answer whether testis-specific lincRNAs indeed regulates the expression of these protein-coding genes requires further investigation.

Although it was previously reported that lncRNAs have a very low sequence conservation among species [8], we used BLAST analysis to investigate the sequence conservation of the mouse testis-specific lncRNAs with human lncRNAs. However, relatively few mouse testis-specific IncRNAs (5.2\%) were found to be conserved in the human lncRNAs. We speculate that the testis-specific lncRNAs may not require sequence conservation to maintain their functionality. Therefore, in the future it will be important to examine the short 
conserved sequences and/or secondary structures of testis-specific lncRNAs.

We used microarray analysis to examine the expression profiles of the selected lncRNAs and mRNAs in the cell lines, F9, GC-1 and GC-2 [], which exhibit germ cell characteristics. A total of 128, 143 and 126 testis-specific lncRNAs and 187, 167 and 175 testis-specific mRNAs were found to be expressed in the F9, GC-1 and GC-2 cell lines, respectively. Fifty five lncRNAs and 105 mRNAs were expressed in an overlapping manner in all of the cell lines. It is possible that these transcripts are expressed during the whole period of spermatogenic stages from which the cell lines were derived. It should be noted that these cell lines do not possess all the characteristics and phenotypes of male germ cells, such as meiosis and spermiogenesis, suggesting weak and/or no expression of some of the testis- or germ cell-specific transcripts in the cell lines. Nonetheless, these cell lines could prove useful for studying the expression and functions of certain testis-specific lncRNAs.

We arbitrarily selected 26 of the novel testis-specific lncRNAs and examined their tissue distributions in 10 mouse tissues. All of the examined lncRNAs were, indeed, specifically expressed in the mouse testis. Additionally, both developmental expression analysis during the first round of spermatogenesis and expression analysis in germ cell-less mutant mice confirmed the germ cell-specificity of these lncRNAs. Interestingly, 16 of the 26 selected lncRNAs were expressed between 16 and 21 days after birth in mouse, suggesting that these IncRNAs undergo a transcriptional change between the late spermatocyte and haploid round spermatid stages. During this period, epigenetic regulation (e.g., DNA methylation and histone modification) occurs actively in testis [44]. As lncRNAs have been implicated in regulating protein-coding genes at the epigenetic level [45], we speculate that these germ-specific lncRNAs may be involved in epigenetic regulation during spermatogenesis.

\section{Conclusions}

We herein used microarray analysis to identify and characterize lncRNAs in mice, and then focused on comprehensively cataloging the lncRNAs specifically found in the testis, which showed the highest proportion of tissue-specific expression. Our findings provide a basis for further investigating the functions of testis-specific lncRNAs, which should improve our understanding of the lncRNA-mediated regulatory mechanisms that may be associated with mouse germ cell development.

\section{Methods}

\section{Animals and tissue preparation}

All animal experiments were performed in accordance with Korean Food and Drug Administration (KFDA) guidelines. Protocols were reviewed and approved by the Institutional Animal Care and Use Committees (IACUC) of Gwangju Institute of Science and Technology (GIST) (permit number: GIST-2017-013). We used 8-week-old ICR male mice (Damul Science, Daejeon, Korea) for our microarray analysis. Mouse brain, heart, kidney, liver and testis tissues were obtained and immediately frozen in liquid $\mathrm{N}_{2}$. Three biological replicates were performed in all cases, and samples were stored at $-80^{\circ} \mathrm{C}$ until use.

\section{Cell culture}

F9 (CRL-1720), GC-1 (CRL-2053) and GC-2 (CRL-2196) cells of mouse origin were obtained from the American Type Culture Collection (ATCC, Manassas, VA, USA) and maintained at $37{ }^{\circ} \mathrm{C}$ and $5 \% \mathrm{CO}_{2}$ in Dulbecco's modified Eagle's medium (DMEM) (Life Technologies, Carlsbad, CA, USA) supplemented with 10\% fetal bovine serum (HyClone, Logan, UT, USA). The culture dishes for the F9 cells were pre-coated with $0.1 \%$ gelatin. Because retinoic acid (RA) is known to induce F9 cell differentiation [46], it was omitted from the medium. The culture media were changed every 1-2 days, and the cells were sub-cultured every 3-4 days. At passages 3 or 4 , cultured cells were collected for RNA extraction.

\section{RNA extraction, quality control and labeling}

Total RNA from five major mouse tissues and three mouse germ cell-related cell lines was isolated with an RNeasy Plus Mini kit (Qiagen, Valencia, CA, USA) according to the manufacturer's instructions. Total RNA was quantified and checked for quality using an ND-1000 spectrophotometer (Thermo Fisher Scientific, Waltham, MA, USA). RNA degradation and DNA contamination were examined by $1 \%$ denaturing agarose gel electrophoresis. RNA samples with RNA Integrity Number (RIN) scores $>8$ were used for microarray analysis. Each $1 \mu \mathrm{g}$ of total RNA was reverse-transcribed into cDNA using a MMLV-RT kit (Life Technologies). The cDNA was transcribed and labeled with Cyanine 3-CTP (Cy3) using a Quick-Amp labeling kit (Agilent, Santa Clara, CA, USA) according to the manufacturer's protocol. The labeled cRNAs were quantified using an ND-1000 spectrophotometer.

\section{Mouse IncRNA microarray analysis}

Total cRNA was hybridized to a Mouse LncRNAs Microarray $(8 \times 60 \mathrm{~K}$; Arraystar $)$ using a hybridization oven (Agilent). The hybridized microarray chip was washed according to the manufacturer's protocol, and the hybridized images were scanned using a DNA microarray scanner and quantified with the Feature Extraction Software (both from Agilent). Data normalization and selection of fold-changed transcripts were performed using GeneSpring GX 7.3 (Agilent). Total lncRNAs and mRNAs were 
detected in three independent sets of the samples in each tissue; those above background were flagged as present or marginal ( $\mathrm{P}$ or $\mathrm{M}$, respectively). For each tissue, specifically expressed lncRNAs and mRNAs were chosen using the following criteria: 1) in three independent samples, they were flagged as $\mathrm{P}$ or $\mathrm{M}$ in a single given tissue but absent (A) in the other tissues; 2) fold-change $\geq 5$; and 3 ) $P$-value $\leq 0.05$. The raw and processed microarray data have been deposited in the Gene Expression Omnibus (GEO) database at the National Center for Biotechnology Information (NCBI), under GEO accession number GSE105024.

\section{Validation of tissue-specific IncRNAs by qRT-PCR}

Total RNA was extracted from five mouse tissues and three germ cell-related cell lines, and reverse-transcribed using RNeasy Plus Mini and Omniscript RT kits (Qiagen). qRT-PCR was carried out using the TOPreal ${ }^{\text {Tw }}$ qPCR 2X premix (Enzynomics, Daejeon, Korea). The reaction volume contained $10 \mu \mathrm{l}$ of TOPreal $^{\mathrm{Tm}}$ qPCR $2 \mathrm{X}$ PreMix, $1 \mu \mathrm{l}$ of $10 \mu \mathrm{M}$ forward and reverse primers, 50$100 \mathrm{ng}$ of template cDNA and $\mathrm{dH}_{2} \mathrm{O}$ to a final volume of $20 \mu \mathrm{l}$. The reactions were performed on a StepOnePlus Real-Time PCR System (Thermo Fisher Scientific) as follows: $95{ }^{\circ} \mathrm{C}$ for $12 \mathrm{~min} 30 \mathrm{~s}$, followed by 40 cycles of $95{ }^{\circ} \mathrm{C}$ for $10 \mathrm{~s}, 60{ }^{\circ} \mathrm{C}$ for $15 \mathrm{~s}$ and $72{ }^{\circ} \mathrm{C}$ for $23 \mathrm{~s}$. The melting curve analysis was performed from $65^{\circ} \mathrm{C}$ to $95^{\circ}$ $\mathrm{C}$ with increments of $0.3{ }^{\circ} \mathrm{C}$. The primer sets used to amplify the selected IncRNAs and control genes are listed in Additional file 10. Amplifications were performed in triplicate for each sample. Relative gene expression levels were evaluated using the $2^{-\Delta \Delta \mathrm{Ct}}$ method [47], and normalized with respect to the level of the endogenous Gapdh mRNA.

\section{Searching for nearby protein-coding genes and gene ontology analysis}

As several lincRNAs act as through a cis-regulatory mechanism [29, 30], we searched for protein-coding genes located in the genomic regions $10 \mathrm{~kb}$ up- and downstream of the testis-specific lincRNAs. We then predicted their functional roles by GO analysis using the DAVID software [48]. GO terms with $P$-value $\leq 0.05$ were considered significantly enriched.

\section{RT-PCR analysis of tissue distribution and developmental expression patterns}

To determine the tissue distribution patterns of 26 testis-specific lncRNAs arbitrarily selected from our microarray analysis, we performed RT-PCR using CDNA from 10 mouse tissues (brain, epididymis, heart, kidney, liver, lung, ovary, skeletal muscle and testis). We also used cDNA from germ cell-lacking testes of $W / W^{N}$ mutant mice to investigate whether these IncRNAs were expressed in somatic cells of testis [37]. To investigate the developmental expression patterns of the selected lncRNAs during the first round of spermatogenesis, total RNA from testes of prepubertal and adult mice $(7 \mathrm{~d}, 8 \mathrm{~d}, 14 \mathrm{~d}, 16 \mathrm{~d}, 21 \mathrm{~d}, 24 \mathrm{~d}, 28 \mathrm{~d}$, 35d, 42d, 49d and 56d) was subjected to RT-PCR. Total RNA was extracted using the TRIzol reagent (Invitrogen, Carlsbad, CA, USA) according to the manufacturer's protocol, and cDNA was synthesized using random hexamers, oligo(dT) primers and Omniscript reverse transcriptase (Qiagen). IncRNA-specific primers were designed using Primer-BLAST and are listed in Additional file 11. Amplification was performed for 35-40 cycles of $95^{\circ} \mathrm{C}$ for $30 \mathrm{~s}, 50{ }^{\circ} \mathrm{C}$ or $55^{\circ} \mathrm{C}$ for $30 \mathrm{~s}$ and $72{ }^{\circ} \mathrm{C}$ for $30 \mathrm{~s}$. Glyceraldehyde-3-phosphate dehydrogenase (Gapdh) were used as a loading control.

\section{Statistical analyses}

All experiments were performed in triplicate for each sample. Statistical analysis was performed using the Student's $t$-test, and $P \leq 0.05$ was taken as indicating a significant difference. Data are presented as the mean \pm standard error of the mean (mean \pm SEM).

\section{Additional files}

Additional file 1: Table S1. LncRNAs and mRNAs in the mouse brain, heart, kidney, liver and testis. (XLSX 18613 kb)

Additional file 2: Table S2. Tissue-specific IncRNAs and mRNAs in the mouse brain, heart, kidney, liver and testis. (XLSX 4020 kb)

Additional file 3: Table S3. The numbers and ratios of testicular IncRNAs and mRNAs on each mouse chromosome. (XLSX $11 \mathrm{~kb}$ )

Additional file 4: Table S4. The numbers and ratios of six types of testicular IncRNA. (XLSX $10 \mathrm{~kb}$ )

Additional file 5: Table S5. Nearby protein-coding genes located within genomic regions $10 \mathrm{~kb}$ up- and downstream of the testis-specific lincRNAs. (XLSX $24 \mathrm{~kb}$ )

Additional file 6: Table S6. GO terms of the nearby protein-coding genes. (XLSX $19 \mathrm{~kb}$ )

Additional file 7: Table S7. Mouse testis-specific IncRNAs that show conservation in human. (XLSX $26 \mathrm{~kb}$ )

Additional file 8: Table S8. LncRNAs and mRNAs in three mouse germ cell-related cell lines (F9, GC-1 and GC-2). (XLSX 16402 kb)

Additional file 9: Table S9. Testis-specific IncRNAs and mRNAs in three mouse germ cell-related cell lines (F9, GC-1 and GC-2). (XLSX 712 kb)

Additional file 10: Table S10. Primers used for qRT-PCR. (XLSX $10 \mathrm{~kb}$ ) Additional file 11: Table S11. Primers used for RT-PCR. (XLSX 11 kb)

\section{Abbreviations}

Agbl3: ATP/GTP binding protein-like 3; Eif2s3y: Eukaryotic translation initiation factor 2, subunit 3, structural gene Y-linked; Glt6d1: Glycosyltransferase 6 domain containing 1; GO: Gene ontology; lincRNA: Long intergenic ncRNA; InCRNA: Long noncoding RNA; miRNA: microRNAs; piRNA: Piwi-interacting RNA; qRT-PCR: Quantitative real-time PCR; Rcc1: Regulator of chromosome condensation 1; Spata17: Spermatogenesis associated 17; Spata31d1d: Spermatogenesis associated 31 subfamily D, member 1D; Speer4e: Spermatogenesis associated glutamate (E)-rich protein 4e; Sry: Sex determining region of Chr Y; Tmco5: Transmembrane and coiled-coil domains 5; Tnp1: Transition protein 1 


\section{Funding}

This work was supported by Mid-career Researcher Program through National Research Foundation of Korea funded by the Ministry of Science, ICT \& Future Planning (NRF-2015R1A2A2A01005300) in the design of the study and writing the manuscript, the Bio \& Medical Technology Development Program of the National Research Foundation of Korea funded by the Ministry of Science, ICT \& Future Planning (NRF 2013M3A9A7046297) in the design of the study and writing the manuscript and GIST Research Institute (GRI), Korea in the design of the study and collection, analysis, and interpretation of data and in writing the manuscript.

\section{Availability of data and materials}

The microarray data can be found in the Gene Expression Omnibus (GEO) database at the National Center for Biotechnology Information (NCBI), under GEO accession number GSE105024.

\section{Authors' contributions}

CC conceived the study. SHH and CC designed the experiments. SHH performed the RNA preparation, cell culture and RT-PCR experiments, and analyzed and interpreted the RT-PCR and microarray data. JTK, JiK, JJ, JaK, and SL contributed reagents, materials and analysis tools, and to the interpretation of the RT-PCR and microarray data. SHH and CC wrote the manuscript. All authors read and approved the final manuscript.

\section{Ethics approval}

All animal experiments were performed in accordance with Korean Food and Drug Administration (KFDA) guidelines. Protocols were reviewed and approved by the Institutional Animal Care and Use Committees (IACUC) of Gwangju Institute of Science and Technology (GIST) (permit number: GIST2017-013)

\section{Consent for publication}

Not applicable.

\section{Competing interests}

The authors declare that they have no competing interests.

\section{Publisher's Note}

Springer Nature remains neutral with regard to jurisdictional claims in published maps and institutional affiliations.

\section{Received: 17 October 2017 Accepted: 5 July 2018}

\section{Published online: 16 July 2018}

\section{References}

1. Eddy EM. Male germ cell gene expression. Recent Prog Horm Res. 2002;57:103-28.

2. Sha J, Zhou Z, Li J, Yin L, Yang H, Hu G, Luo M, Chan HC, Zhou K, Spermatogenesis study $\mathrm{g}$. Identification of testis development and spermatogenesis-related genes in human and mouse testes using cDNA arrays. Mol Hum Reprod. 2002;8(6):511-7.

3. Hayashi K, Chuva de Sousa Lopes SM, Kaneda M, Tang F, Hajkova P, Lao K, O'Carroll D, Das PP, Tarakhovsky A, Miska EA, et al. MicroRNA biogenesis is required for mouse primordial germ cell development and spermatogenesis. PLoS One. 2008;3(3):e1738.

4. Gan H, Lin X, Zhang Z, Zhang W, Liao S, Wang L, Han C. piRNA profiling during specific stages of mouse spermatogenesis. RNA. 2011;17(7):1191-203.

5. Soumillon M, Necsulea A, Weier M, Brawand D, Zhang X, Gu H, Barthes P, Kokkinaki M, Nef S, Gnirke A, et al. Cellular source and mechanisms of high transcriptome complexity in the mammalian testis. Cell Rep. 2013:3(6):2179-90.

6. Dinger ME, Amaral PP, Mercer TR, Pang KC, Bruce SJ, Gardiner BB, AskarianAmiri ME, Ru K, Solda G, Simons C, et al. Long noncoding RNAs in mouse embryonic stem cell pluripotency and differentiation. Genome Res. 2008; 18(9):1433-45

7. Pauli A, Valen E, Lin MF, Garber M, Vastenhouw NL, Levin JZ, Fan L, Sandelin A, Rinn JL, Regev A, et al. Systematic identification of long noncoding RNAs expressed during zebrafish embryogenesis. Genome Res. 2012;22(3):577-91.

8. Kutter C, Watt S, Stefflova K, Wilson MD, Goncalves A, Ponting CP, Odom DT, Marques AC. Rapid turnover of long noncoding RNAs and the evolution of gene expression. PLoS Genet. 2012;8(7):e1002841.

9. Ulitsky I, Bartel DP. lincRNAs: genomics, evolution, and mechanisms. Cell. 2013;154(1):26-46.
10. Cabili MN, Trapnell C, Goff L, Koziol M, Tazon-Vega B, Regev A, Rinn JL. Integrative annotation of human large intergenic noncoding RNAs reveals global properties and specific subclasses. Genes Dev. 2011;25(18):1915-27.

11. Mercer TR, Dinger ME, Sunkin SM, Mehler MF, Mattick JS. Specific expression of long noncoding RNAs in the mouse brain. Proc Natl Acad Sci U S A. 2008;105(2):716-21.

12. Vance $\mathrm{KW}$, Ponting $\mathrm{CP}$. Transcriptional regulatory functions of nuclear long noncoding RNAs. Trends Genet. 2014;30(8):348-55.

13. Rinn $J$, Chang HY. Genome regulation by long noncoding RNAs. Annu Rev Biochem. 2012;81:145-66.

14. Holoch D, Moazed D. RNA-mediated epigenetic regulation of gene expression. Nat Rev Genet. 2015;16(2):71-84

15. Mercer TR, Mattick JS. Structure and function of long noncoding RNAs in epigenetic regulation. Nat Struct Mol Biol. 2013;20(3):300-7.

16. Gonzalez I, Munita R, Agirre E, Dittmer TA, Gysling K, Misteli T, Luco RF. A IncRNA regulates alternative splicing via establishment of a splicing-specific chromatin signature. Nat Struct Mol Biol. 2015;22(5):370-6.

17. Bardou F, Ariel F, Simpson CG, Romero-Barrios N, Laporte P, Balzergue S, Brown JW, Crespi M. Long noncoding RNA modulates alternative splicing regulators in Arabidopsis. Dev Cell. 2014;30(2):166-76.

18. Gong C, Maquat LE. IncRNAs transactivate STAU1-mediated mRNA decay by duplexing with 3' UTRs via Alu elements. Nature. 2011;470(7333):284-8.

19. Kretz M, Siprashvili Z, Chu C, Webster DE, Zehnder A, Qu K, Lee CS, Flockhart RJ, Groff AF, Chow J, et al. Control of somatic tissue differentiation by the long non-coding RNA TINCR. Nature. 2013:493(7431):231-5.

20. Fatica A, Bozzoni I. Long non-coding RNAs: new players in cell differentiation and development. Nat Rev Genet. 2014;15(1):7-21.

21. Grote $P$, Wittler $L$, Hendrix D, Koch F, Wahrisch $S$, Beisaw A, Macura K, Blass G, Kellis $M$, Werber $M$, et al. The tissue-specific IncRNA Fendrr is an essential regulator of heart and body wall development in the mouse. Dev Cell. 2013;24(2):206-14.

22. Mathieu EL, Belhocine M, Dao LT, Puthier D, Spicuglia S. Functions of IncRNA in development and diseases. Med Sci (Paris). 2014:30(8-9):790-6.

23. Sun J, Lin $Y$, Wu J. Long non-coding RNA expression profiling of mouse testis during postnatal development. PLoS One. 2013:8(10):e75750.

24. Liang M, Li W, Tian H, Hu T, Wang L, Lin Y, Li Y, Huang H, Sun F. Sequential expression of long noncoding RNA as mRNA gene expression in specific stages of mouse spermatogenesis. Sci Rep. 2014;4:5966.

25. Bao J, Wu J, Schuster AS, Hennig GW, Yan W. Expression profiling reveals developmentally regulated IncRNA repertoire in the mouse male germline. Biol Reprod. 2013;89(5):107.

26. Anguera MC, Ma W, Clift D, Namekawa S, Kelleher RJ 3rd, Lee JT. Tsx produces a long noncoding RNA and has general functions in the germline, stem cells, and brain. PLoS Genet. 2011;7(9):e1002248.

27. Akhade VS, Dighe SN, Kataruka S, Rao MR. Mechanism of Wnt signaling induced down regulation of mrhl long non-coding RNA in mouse spermatogonial cells. Nucleic Acids Res. 2016;44(1):387-401.

28. Yu YE, Zhang Y, Unni E, Shirley CR, Deng JM, Russell LD, Weil MM, Behringer RR, Meistrich ML. Abnormal spermatogenesis and reduced fertility in transition nuclear protein 1-deficient mice. Proc Natl Acad Sci U S A. 2000;97(9):4683-8.

29. Trimarchi T, Bilal E, Ntziachristos P, Fabbri G, Dalla-Favera R, Tsirigos A Aifantis I. Genome-wide mapping and characterization of notch-regulated long noncoding RNAs in acute leukemia. Cell. 2014:158(3):593-606.

30. Yap KL, Li S, Munoz-Cabello AM, Raguz S, Zeng L, Mujtaba S, Gil J, Walsh MJ, Zhou MM. Molecular interplay of the noncoding RNA ANRIL and methylated histone $\mathrm{H} 3$ lysine 27 by polycomb CBX7 in transcriptional silencing of INK4a. Mol Cell. 2010;38(5):662-74

31. Huang d W, Sherman BT, Lempicki RA. Systematic and integrative analysis of large gene lists using DAVID bioinformatics resources. Nat Protoc. 2009:4(1):44-57.

32. Altschul SF, Gish W, Miller W, Myers EW, Lipman DJ. Basic local alignment search tool. J Mol Biol. 1990;215(3):403-10.

33. Alonso A, Breuer B, Steuer B, Fischer J. The F9-EC cell line as a model for the analysis of differentiation. Int J Dev Biol. 1991;35(4):389-97.

34. Kwon JT, Jin S, Choi H, Kim J, Jeong J, Kim J, Kim Y, Cho BN, Cho C. Identification and characterization of germ cell genes expressed in the F9 testicular teratoma stem cell line. PLoS One. 2014;9(8):e103837.

35. Hofmann MC, Narisawa S, Hess RA, Millan JL. Immortalization of germ cells and somatic testicular cells using the SV40 large T antigen. Exp Cell Res. 1992;201(2):417-35.

36. Hofmann MC, Hess RA, Goldberg E, Millan JL. Immortalized germ cells undergo meiosis in vitro. Proc Natl Acad Sci U S A. 1994;91(12):5533-7. 
37. Geissler EN, Ryan MA, Housman DE. The dominant-white spotting (W) locus of the mouse encodes the c-kit proto-oncogene. Cell. 1988;55(1):185-92.

38. Bellve AR, Cavicchia JC, Millette CF, O'Brien DA, Bhatnagar YM, Dym M. Spermatogenic cells of the prepuberal mouse. Isolation and morphological characterization. J Cell Biol. 1977;74(1):68-85.

39. Chalmel F, Lardenois A, Evrard B, Rolland AD, Sallou O, Dumargne MC Coiffec I, Collin O, Primig M, Jegou B. High-resolution profiling of novel transcribed regions during rat spermatogenesis. Biol Reprod. 2014;91(1):5.

40. Ran M, Chen B, Li Z, Wu M, Liu X, He C, Zhang S, Li Z. Systematic identification of long noncoding RNAs in immature and mature porcine testes. Biol Reprod. 2016;94(4):77.

41. Koopman P, Gubbay J, Vivian N, Goodfellow P, Lovell-Badge R. Male development of chromosomally female mice transgenic for Sry. Nature. 1991;351(6322):117-21

42. Mazeyrat S, Saut N, Grigoriev V, Mahadevaiah SK, Ojarikre OA, Rattigan A, Bishop C, Eicher EM, Mitchell MJ, Burgoyne PS. A Y-encoded subunit of the translation initiation factor Eif2 is essential for mouse spermatogenesis. Nat Genet. 2001;29(1):49-53.

43. Mercer TR, Dinger ME, Mattick JS. Long non-coding RNAs: insights into functions. Nat Rev Genet. 2009;10(3):155-9.

44. Sasaki H, Matsui Y. Epigenetic events in mammalian germ-cell development: reprogramming and beyond. Nat Rev Genet. 2008;9(2):129-40.

45. Cao J. The functional role of long non-coding RNAs and epigenetics. Biol Proced Online. 2014;16:11.

46. Lehtonen E, Laasonen A, Tienari J. Teratocarcinoma stem cells as a model for differentiation in the mouse embryo. Int J Dev Biol. 1989:33(1):105-15.

47. Livak KJ, Schmittgen TD. Analysis of relative gene expression data using real-time quantitative PCR and the 2(-Delta Delta $C(T))$ method. Methods. 2001;25(4):402-8

48. Huang DW, Sherman BT, Tan Q, Kir J, Liu D, Bryant D, Guo Y, Stephens R, Baseler MW, Lane HC, et al. DAVID bioinformatics resources: expanded annotation database and novel algorithms to better extract biology from large gene lists. Nucleic Acids Res. 2007;35(Web Server issue):W169-75.

Ready to submit your research? Choose BMC and benefit from:

- fast, convenient online submission

- thorough peer review by experienced researchers in your field

- rapid publication on acceptance

- support for research data, including large and complex data types

- gold Open Access which fosters wider collaboration and increased citations

- maximum visibility for your research: over $100 \mathrm{M}$ website views per year

At $\mathrm{BMC}$, research is always in progress.

Learn more biomedcentral.com/submissions 